\title{
Students' Intuition in Mathematics Class Using Lesson Study and Open Approach
}

\author{
Kwanta Panbanlame', Kiat Sangaroon ${ }^{2}$, Maitree Inprasitha ${ }^{3}$ \\ ${ }^{1}$ Doctoral Program in Mathematics Education, Khon Kaen University, Khon Kaen, Thailand \\ ${ }^{2}$ Department of Mathematics, Faculty of Science, Khon Kaen University, Khon Kaen, Thailand \\ ${ }^{3}$ Center for Research in Mathematics Education, Khon Kaen University, Khon Kaen, Thailand \\ Email: mamkwanta@hotmail.com
}

Received 2 July 2014; revised 26 July 2014; accepted 16 August 2014

Copyright (C) 2014 by authors and Scientific Research Publishing Inc.

This work is licensed under the Creative Commons Attribution International License (CC BY). http://creativecommons.org/licenses/by/4.0/

(c) (i) Open Access

\begin{abstract}
The objective of this article is to investigate students' intuition in mathematics class using Lesson Study and Open Approach. The research methodology employed was the qualitative research methods of teaching experiment combined with an ethnographic study. The study's target group consists of three Grade 2 students at Ban Bueng Niam Bueng Krainoon School in Khon Kaen Province during the 2012 Academic Year. This is the school that participated in the professional development of mathematics teachers with Lesson Study and Open Approach innovation project. The researcher collected data from a mathematics class that taught multiplication learning unit (1) from the mathematics textbook for Grade 2 students. This is the textbook used in the professional development of mathematics teachers with Lesson Study and Open Approach innovation project. The research findings are: Mathematics class using Lesson Study and Open Approach allows students to intuitively learn the content of a basic multiplication unit. Students' intuition was developed during Step 1 (posing open-ended problems) and Step 2 (students' self-learning through problemsolving) of the Open Approach process. Students intuitively discovered the repeated addition and multiplication methods in solving multiplication problems.
\end{abstract}

\section{Keywords}

Intuition, Lesson Study, Open Approach

\section{Introduction}

Lesson Study is the topic that has attracted worldwide interest. It is a process for teaching development through collaboration with other teachers, who study and comment on the teaching technique of another teacher. Lesson 
Study was initially developed as an educational practice in Japan during the Meiji era and is a key technique that enables teachers to study and improve their own teaching methods. It is through this educational development potential that Lesson Study has garnered international interest (Baba, 2007). Lesson Study is the professional learning process that Japanese teachers engage in throughout their career to monitor and develop different teaching methods in terms of content and curriculum. It is also used to systematically monitor students' learning process in order to achieve the educational goals (Yoshida, 2008).

The current education system in Thailand mainly adopts rote learning instruction in which teachers lecture and demonstrate examples to the class so that students can follow their methods in problem solving. It is the academic achievement-based instruction system that focuses on students' test scores rather than on students' learning process or learning method. Most mathematics teachers fail to realize that content-based teaching, which emphasizes the teaching of mathematical formulas, rules and principles, and getting students to practice extensive number of problems so that they can memorize the contents, is more akin to telling students about mathematics than teaching them mathematics. This teaching method does not encourage logical thinking and stifles students' enthusiasm and creativity (Inprasitha, 2003). Following Thailand's educational reform in 1999, the majority of teachers have attempted to improve their teaching but lacked the innovation to do so. Most teachers still adopt the traditional teaching method of content-based lecturing while overlooking the importance of students' learning process and fail to understand students' attitudes (Inprasitha, 2006).

Inprasitha and Loipha (2004) proposed that Lesson Study is an innovation whose fundamental concepts reflect the most efficient measure for classroom teaching improvement and development, which is the development and improvement of class lessons in the actual classroom contexts. The challenging features of Lesson Study include how to induce the desired changes in classroom to improve learners' learning process, how to share classroom knowledge and problems with other teachers, and how to raise teachers' awareness about the goals of group teaching. Lesson Study innovation has been adapted and implemented in Thai schools' mathematics classes since 2002 under the initiative of Assistant Professor Dr. Maitree Inprasitha, a lecturer at the Faculty of Education, Khon Kaen University (Inprasitha, 2004). The Lesson Study process consists of three major phases. Phase 1 -Collaboratively designing research lesson. The research team and participating teachers use Open Approach to collaboratively design the research lesson. The planned learning unit is based on open-ended problems. Phase 2-Collaboratively observing the research lesson. The learning plan is implemented in real-life classroom situations. Representatives of the lesson planning team act as teacher and classroom observers. The goal of this step is to observe students' thinking process. Phase 3-Collaboratively doing post-discussion or reflection on teaching practice. Teaching observation data are discussed and reflected to improve the learning management plan.

Open Approach is a 4-step teaching approach that comprises the following four steps: Posing open-ended problem, Students' self-learning, Whole class discussion and comparison of concepts, and Summarization through connecting students' mathematical ideas emerged in the classroom (Inprasitha, 2010). The characteristics of Open Approach classrooms include the use of open-ended problems that have been designed to pressure students into creating a mathematical problem from the presented on their own. While students search for different alternatives to solve the problem, they are expected to discover their own problem-solving method based on their own past experiences. Open-ended problems provide students with the opportunity to fully utilize their potential and to have a freedom of thought to carry out the assigned activities. They also promote mathematical thinking and encourage the search for individualized learning (Nohda, 2000). Open-ended problems are designed with students' thinking approach in mind. Teachers must observe students' thinking approach while in a classroom and use the questions to stimulate students into expressing their thinking approach by themselves. Open Approach classroom is likely to provide students with an opportunity to express mathematical thinking through their own intuition in order to discover the mathematical rules, formulas or principles by themselves.

The researcher participated in the Lesson Study and Open Approach classroom situation as a school coordinator and a researcher who helped with designing the learning plan. The researcher also observed Grade 1 and Grade 2 mathematical classes and participated in the discussion and reflection sessions at Ban Bueng Niam Bueng Krai Noon School, a participating school in the professional development of mathematics teachers with Lesson Study and Open Approach innovation research project conducted by the Center for Research in Mathematics Education, Faculty of Education, Khon Kaen University during the 2009-2010 Academic Years. The researcher identified the special characteristic of Ban Bueng Niam Bueng Krai Noon School's mathematical classes as operating under the Lesson Study and Open Approach innovation. From the perspective of students' mathematic learning process promotion, this school implemented the Open Approach that focus on prob- 
lem-solving instruction. These school's characteristics provided students with the opportunity to participate in problem situation teaching and to develop various responses to such mathematical problems. Learning activities, in the forms of open-ended problems from Japanese textbooks in the classrooms, were implemented at the school. The open-ended problems were designed to pressure students into creating mathematical problems from the problem situations by themselves. They were able to significantly draw students' potential for mathematical process which led them to discover mathematical formulas, rules, and principles on their own (Inprasitha, 2003).

Mathematics should be considered from two perspectives. From one perspective, mathematics is considered the beliefs, agreements, rules, definitions, and systematic knowledge that are accepted as truthful. This type mathematics is the one that appears in academic articles and advanced textbooks. From the other perspective, mathematics is considered the human activities with three fundamental elements: Formal aspect, Algorithmic aspect, and Intuitive aspect. These three elements may sometimes merge (Fischbein, 1994). As human activities, mathematics plays a vital role in the development of human thoughts. The general public is mainly interested in mathematicians for their mathematical creativity; they want to know how the mind of mathematicians works when they do mathematics. They use insight and intuition in the process of producing mathematics creativity (Kilpatrick, 1992). Intuition is the intellectual technique of arriving at plausible but tentative formulations without going through the analytic steps by which such formulations would be found to be valid or invalid conclusions (Bruner, 1960: p. 13). Bruner wanted learners to develop this type of thinking as much as possible and considered it a form of academic guessing that will generate more creativity. This is consistent with Polya's (Polya, 1954: p. vi) belief that let us learn proving, but also let us learn guessing.

Fischbein reacted to Piaget's definition of "intuition" as being all forms of informal cognition. However, Piaget did not make a distinction between intuitive and non-intuitive cognition during the concrete-operational level of human development. Fischbein examined the differences between the logical answers that are both acceptable and intuitive and the answers that are derived from a thinking and analytical process. This distinction is significant in terms of learning psychology and teaching method. Intuitively acceptable problem-solving method is more directly and intensively associated with an individual than with non-intuitive analytical thinking. It is, therefore, important to offer a teaching/learning method that can evaluate students' basic intuitive reaction to a problem. If students' basic intuitions are unsuitable, they may result in conflicting learning situations (Fischbein, 1987).

Gelman demonstrated that preschool children can significantly acquire counting principles even before they can verbally express their feelings or thoughts. There are 5 counting principles: 1 ) The one-one principle; 2) The stable order principle; 3) The cardinal principle; 4) The abstraction principle; and 5) The order-irrelevance principle (Gelman and Gallistel, 1978 cited in Gelman, 1980). Gelman also found pre-school children to be able to make numerical reasoning (Gelman, 1980, 1982). During the initial schooling period, young children use quantitative schema to solve arithmetic problems with success (Ben-Zeev \& Star, 2001). For multiplication, Anghileri (1989) and Mulligan and Michelmore (1997) revealed that students use three types of intuition in multiplication, namely, counting, repeated addition, and multiplication.

These studies indicated that students possess certain principles that allow them to efficiently make correct reasoning. However, it is very difficult for them to apply such mathematics learning method to school mathematics. "Why are small children's intuitions ineffective with school mathematics learning?” (Resnick, 1986: p. 161 cited in Ben-Zeev \& Star, 2001). This is the question that provides an impetus for numerous researches on mathematics learning. One of the answers to this question is because school mathematics put an emphasis on rote learning and symbol management. Too much emphasis on following correct mathematical steps may discourage and prevent students from applying their intuition to school mathematics learning (Hiebert \& Lefevre, 1986 cited in Ben-Zeev \& Star, 2001). Many teachers show negative reactions to students' suggestion on a method or a strategy for problem solving before using systematic reasoning to respond to the problems. Such reactions from the teacher often discourage students from expressing their view when they participate in classroom problem solving. There should be more studies on the ability to anticipate the probability of intuitive problem solving. However, this cannot be done if students never have a chance to confront their friends' or teachers' ideas with their intuition in the classroom (Fischbein, 1999).

For the reasons stated above, the researcher is interested in investigating students' intuition in mathematics class using Lesson Study and Open Approach.

\section{Theoretical Framework}

In this study, mathematics classroom using Lesson Study and Open Approach is defined as a classroom that 
comprises: 1) The teachers who participate in the Lesson Study process and Open Approach as the teaching method; 2) The problem situations that were collaboratively created by the teachers and a team of Lesson Study research based on the problem situations in the multiplication learning unit (1) in Chapter 9 of Grade 2 mathematics textbook. This is the textbook used in the professional development of mathematics teachers with Lesson Study and Open Approach innovation; 3) The students who have been taught by teachers who participated in the Lesson Study process and Open Approach as the teaching method since Grade 1.

\subsection{Lesson Study}

Lesson Study is the topic that has attracted the public interest all over the world. Educators have adapted Lesson Study for learning/teaching management and for the profession development of teachers. Inprasitha (2010) stated that Thailand has adapted the Japanese Lesson Study to the Thai classrooms since 2002. There are three phases in the Lesson Study process: collaboratively designing research lessons, collaboratively observing research lessons, and collaboratively doing post-discussion or reflection on the teaching practice.

\subsection{Open Approach}

Open-ended approach is the teaching method developed by Shigeru Shimada with an emphasis on the more advanced goals of mathematics learning and learning evaluation. Since "ability to mathematize" is the most expected goal in mathematics teaching and learning, open-ended problems have been developed for the evaluation of such ability and are considered to have made positive contribution to classroom management efficiency. Openended problems have become a classroom teaching method through the teaching method known as Open-ended approach (Ikeda, 2010). Nohda (2000) considered Open Approach to be the method of instruction that can be adapted to a variety of students' thinking styles. In other words, students' mathematical thinking and mathematical perspective must be integrated with new teaching/learning innovation to generate distinctive characteristics of mathematics education and mathematics education research. Inprasitha (2010) stated that implementation of Thailand's educational reform under the 1999 National Education Act has compelled teachers to improve on their teaching skills However, it is unfortunate that teachers lack the innovation to improve their routine responsibilities; most of them still cling to the old method of content teaching and tend to overlook the importance of students' learning process and of the learning with understanding through "problem-solving oriented classroom" concept. Open Approach has been integrated with Lesson Study and adopted as a teaching method in the Lesson Study process. Open Approach consists of four major steps: Step 1-Posing open-ended problems, Step 2-Students' self learning through problem solving, Step 3-Whole class discussion and comparison, and Step 4-Summarization through connecting students' mathematical ideas emerged in the classroom.

\subsection{Intuition}

Fischbein (1999) distinguished between affirmatory intuitions and anticipatory intuitions. Affirmatory intuitions are direct and self-evident cognition without the need for checking or proving, a sense of intrinsic conviction of one's ideas without any extrinsic encouragement. Affirmative intuitions influence students' reasoning on the selection of a particular hypothesis and strategy. They are the inductive ability that students use in addition to the existing empirical data and the holistic cognition. They do not require any procedural analysis in the form of the statements that reflect students' interpretation, ideas or strategies. Anticipatory intuitions are the cognition that implicitly emerges during an attempt at problem solving, immediately after a serious search for a problem-solving strategy. Anticipatory intuitions are holistic and associated with the feeling of conviction derived from comprehensive reasoning or proving. Fischbein introduced the notion that an intuition is, generally, the effect of a compression of data, if a structural schema lies behind this cognitive process. Fischbein referred to Thurston's assertion about the important role of compression in mathematical reasoning that, "Mathematics is amazingly compressible: you may struggle a long time, step by step, to work through some process or idea from several approaches. But once you really understand it and have the mental perspective to see it as a whole, there is often a tremendous mental compression” (Thurston, 1990: p. 847).

\section{Research Methodology}

Ethnographic study was used to collect basic data on the context of the mathematic classes using Lesson Study 
and Open Approach and the basic data of the target group. The researcher used participant observation technique for observation of students in the mathematics class context in order to understand student behaviors in terms of their responses to the problems, their approach to problem solving, their problem-solving concepts and methods. Participant observation was conducted throughout the 2011 Academic Year in Grade 1 mathematics class and in the first semester of the 2012 Academic Year in Grade 2 mathematics class. The target group in the study consisted of three students. This method was also used to get the overall of the social interactions that took place in the mathematics classes using the Lesson Study and Open Approach of Ban Bueng Niam Bueng Krai Noon School. Apart from participant observation, field records and interviews were also used to collect data. The researcher joined the Lesson Study team in their study. This team consisted of a researcher, an assistant researcher, a class teacher, and a teacher observer. Details of the Lesson Study sessions are as follows:

Phase 1: The researcher joined members of the Lesson Study team in designing the lesson plans. The team first discussed among themselves for the developing of open-ended problems, which were the problem situations that provided students with an opportunity to make a response on their own. It then designed the materials to promote and stimulate students' responses so that they could create and develop mathematical concepts. It mutually anticipated students' problem-solving concepts or methods and derived mutual understandings about students' responses to the problem situations as well as about students' problem-solving concepts and methods. The team also discussed and determined the instruction steps under the Open Approach method, based on Inprasitha's (Inprasitha, 2010) ideas of creating a problem-solving classroom that provides students with an opportunity for self-learning and responding to the problem situations on their own. Students are encouraged to naturally develop mathematical concepts or principles or ideas. The Open Approach instruction steps were: 1) Posing open-ended problem; 2) Students' self-learning; 3) Whole class discussion and comparison of concepts; and 4) Summarization through connecting students' mathematical ideas emerged in the classroom. The researcher collaborated in the writing up of the lesson plans throughout the 2011 Academic Year and during Semester 1 of the 2012 Academic Year. The School held a lesson plan writing up session once a week on every Tuesday.

Phase 2: Classroom observation by the researcher. During this period the class teacher applied the lesson plans, jointly prepared by the researcher and the Lesson Study team, to the mathematics classes. The researcher joined the classes as an observer of the overall of the social interactions and events that occurred. The observation focused on students' responses to the problem situations, their problem-solving approaches, and mathematical concepts or methods that emerged during the problem-solving process. Participant observation by the researcher was conducted in Grade 1 mathematics class throughout the 2011 Academic Year and in Grade 2 class during Semester 1 of the 2012 Academic Year.

Phase 3: Class reflection session participation by the researcher. During this period, the researcher and the Lesson Study team reflected on the events that took place in the classes with special emphasis on students' responses to the problem situations, their problem-solving approaches, their mathematics concepts or methods that emerged during the problem-solving process. They discussed the students' emerged mathematical concepts and the students' mathematical anticipation anticipated by the team. The researcher joined these reflection sessions throughout the 2011 Academic Year and during Semester 1 of the 2012 Academic Year. The School held a reflection session once a week on every Thursday.

To conduct an investigation on students' intuition in mathematics class using Lesson Study and Open Approach, data were collected from the target group of three students on the basic multiplication content taught in Grade 2 class during Semester 2 of the 2012 Academic Year. Teaching experiment research and ethnographic study methodologies were used. The researcher entered the classroom as an observer and collaborated with a Lesson Study team comprising a researcher, an assistant researcher, a class teacher, and a teacher observer and participated in all three of the Lesson Study Phases. The teaching experiment in this research involved the administration and presentation of information through the problem situations taken from Japanese mathematics textbooks on the topic of Multiplication (1) over five class periods. The primary objective of the teaching experiment was to enable the researcher to experience and explicate the intuition of individual student on the concept of basic multiplication. The teaching experiment used here involved a sequence of teaching episodes which consisted of a team representative who taught the students, teaching episode eyewitnesses, and the recording of the teaching episode events. Members of the Lesson Study team jointly designed the lesson plans and determined the Open Approach instruction based on the ideas of Inprasitha (2010). The emphasis was on creating a problem-solving classroom and providing students with the opportunity to develop mathematical concepts or principles naturally and on their own. The jointly designed lesson plans were taught in mathematics class by a 
teacher who was a member and a representative of the Lesson Study team. The lesson plans' learning activities were implemented in mathematics class and were observed by the remaining members of the team, namely, the researcher, assistant researcher, and teacher observer. These people were considered teaching episode eyewitnesses. In addition, field records and videotaping of teacher and students and classroom incidents, which were the teaching episodes of this study, were also taken. Afterward, all members of the Lesson Study team collectively reflected what happened in the classroom in order to use the data to improve the lesson plan designs. After all data were collected, triangulation was used to cross-check the research findings. Investigator triangulation involved the use of the researcher, assistant researcher and class teacher to obtain data through target group observations. After classroom observation the researcher, assistant researcher and class teacher again watched the videotapes together and discussed the events. For data triangulation, the researcher used videotape and protocol data, interview data, and students' works.

\section{Data Analysis}

Data analysis was done by analyzing videos, protocols, and descriptive interpretation, using Inprasitha's (Inprasitha, 2010) 4-step Open Approach-based teaching. The analysis aims to investigate students' intuition and to reflect how the Open Approach allows students to handle their intuition. Data on students' intuition were analyzed by Fischbein's (Fischbein, 1999) concept.

Data analysis examples

The researcher will present an analysis of Baitoey, a student in the target group, during the "Fun Party 1" activity (Figure 1).

As a result, Baitoey intuitively discovered the repeated addition and multiplication throughout this activity. This is the first activity that students were confronted with the problem situations in multiplication that were designed by the Lesson Study research team to stimulate and encourage students to handle their intuition. The problem situations must have accompanying images and narratives.

"Fun Party 1" activity was presented through the problem situation of "Last night I (the teacher) was at a party. Can you guess what items were at the party? Find out the number of the items I found there?

InstructionStudents are to find a way to figure out the number of various items on the plates.

Write down the total numbers of each item on the activity sheet.

Step 1: Posing open-ended problems

The teacher posed a problem situation by narrating a story and showing images depicting the problem situation to stimulate students' enthusiasm to solve the problem. Figure 2 shows students' enthusiasm to comprehend the problem and answer the teacher's questions. For example,

Teacher: Do you know the total number of each type of sweet and fruit?

Baitoey: Two.

Teacher: Only two?

Baitoey: Donuts and cakes.

Teachers: I asked how many cakes there are. Does anyone know?

Baitoey: Sixteen.

Teacher: Do you count them in piece?

Baitoey: I count them as two.

Teacher: You count them as two? How so?

Baitoey: There are two of them. So I count them two at a time.

The student still exhibits the desire to solve the problem herself, for instance.

Teacher: Would you like to find out the total number of the items? Can you do that?

Baitoey: Yes, I would like to. I can do that.

Baitoey made an intuitive statement "There are two of them. So I count them two at a time". This is the method she used to find the number of cakes. In this step we can see that the student speculate a problem-solving method by using what she had previously learned before proceeding to solve the problem in the next step by herself.

Step 2: Student's self-learning through problem solving.

Baitoey considered the content directly from the information supplied by the question and the accompanying images. She read the question again by herself and considered the image from the question. She then tried vari- 


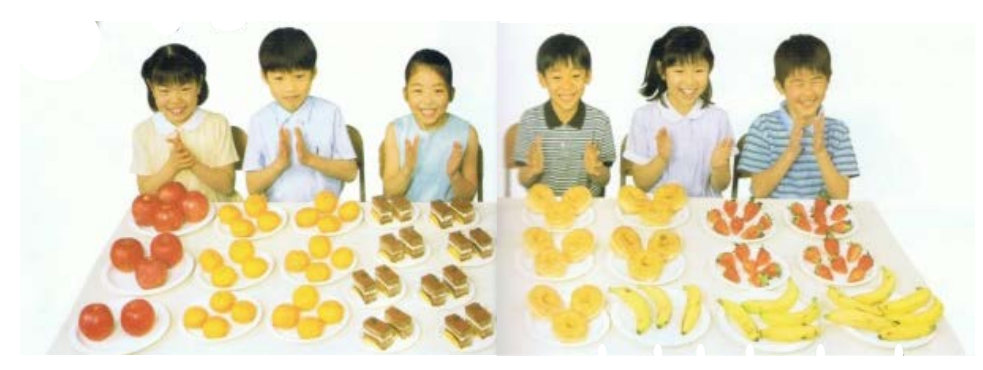

Figure 1. “Fun Party 1” activity (Gakkoh Tosho Co., Ltd., 2005).
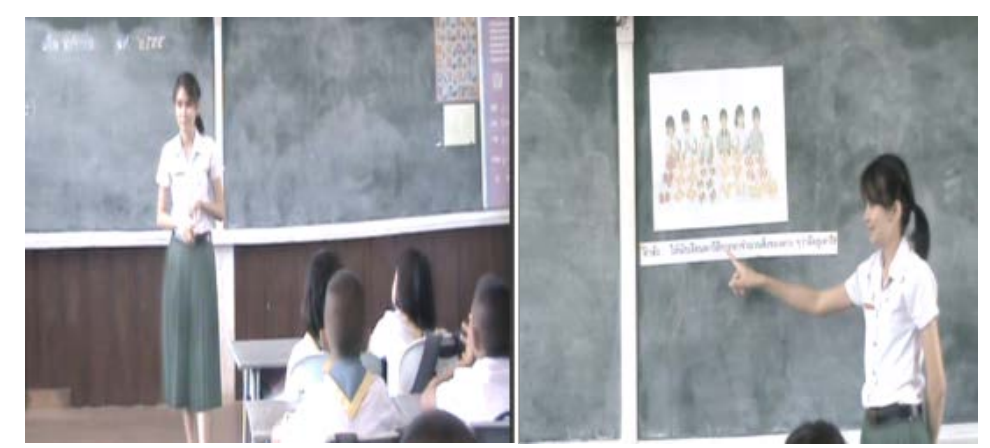

Figure 2. The teacher poses a problem situation by telling a story and showing images.

ous problem-solving methods to reach a solution by using what she had previously learned, as seen in the following protocol.

Teacher: How should you find out?

Baitoey: Pair them. [Grinning when answering the question].

Teacher: Oh? How do you pair them? How do you pair them? How do you pair them?

Baitoey: Draw nine blocks. [Smiling and talking].

Teacher: Where? What comes in nine?

Baitoey: [Smiled and spoke] Apples.

Teacher: Where did this nine come from?

Baitoey: Nine comes from the apples.

Teacher: How did you count them? How to count them?

Baitoey: Three at a time.

Teacher: How to count them?

Baitoey: [With a pencil pointed to the image of the apples, one plate at a time, she counted out loud with a smiling face].

Three, Six, Nine.

Teacher: Let's see. Three, Six, Nine. [Pointed at the image with two apples on a plate].

There are two here, how come you counted them as three?

Baitoey: [Looking up at the teacher, she then looked down at the image and pointed with the pencil].

I added one from here.

Teacher: Where did you add it from?

Baitoey: I took this apple and put it there. [She pointed at one apple in the middle plate and drew a line to the plate with two apples].

Teacher: If you take this apple away, how many are left?

Baitoey: There are two left. [Speaking in a confident voice].

Teacher: Can you show me how you put it there?

Baitoey: [With a determined expression on her face, she drew a line from one apple in the middle plate to the plate with two apples, and then drew a line from one apple in the plate with four apples to the middle plate with two apples remaining]. 


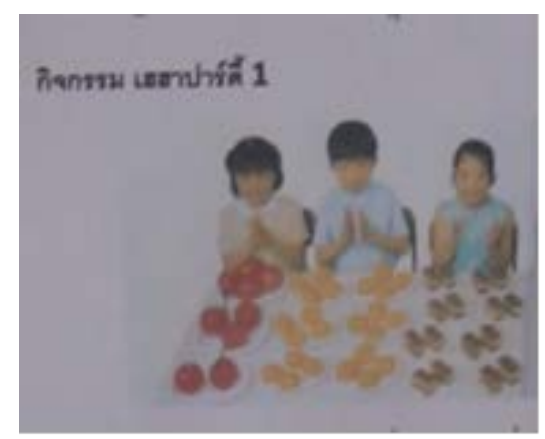

Baitoey: [Baitoey began to work, beginning with writing down the word "9 apples" and drew blocks in two parallel rows, pairs of top and bottom rows. This was repeated four times. One more block was drawn on the top row. She then drew a line connecting each pair of the top and bottom blocks].

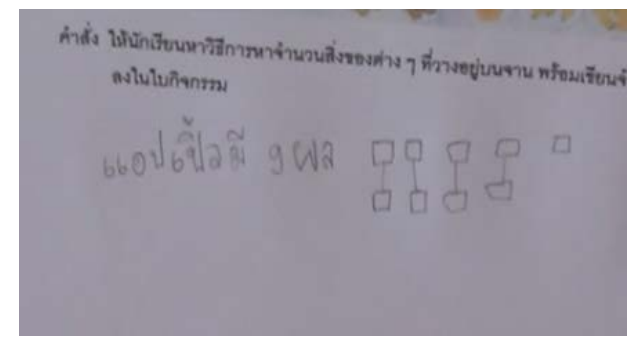

Baitoey: [With a thoughtful face she held the pencil as if to erase what was written but did not. She then picked up the pencil again in preparation for more writing, and then used the pencil to count the oranges].

Baitoey: [Wrote the phrase "There are 24 oranges" on the paper].

Baitoey: [With the eraser-end of the pencil, she pointed to the images of apples].

Three, Three, Three.

Baitoey: [Wrote the number "3" above the first pair of the blocks. She stopped to think for about 10 seconds, then erased the number " 3 " that she just wrote and proceeded to erase all the blocks that were drawn].

Baitoey: [Drew three vertical rows of three blocks, then wrote the number "3" above each row of blocks, then drew a line connecting all the blocks in each vertical row].

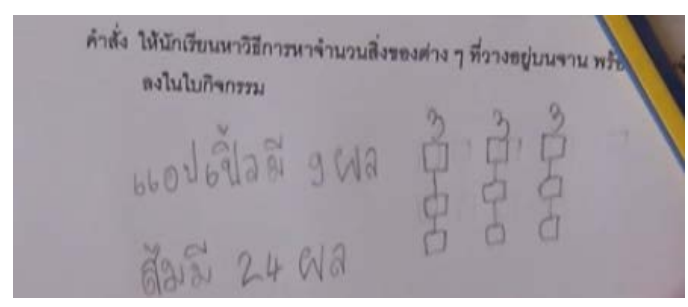

Baitoey: [Erased the phrase “There are 24 oranges”, then turned the pencil around and prepared to write. After about 20 seconds the student wrote $3+3+3=9$ ].
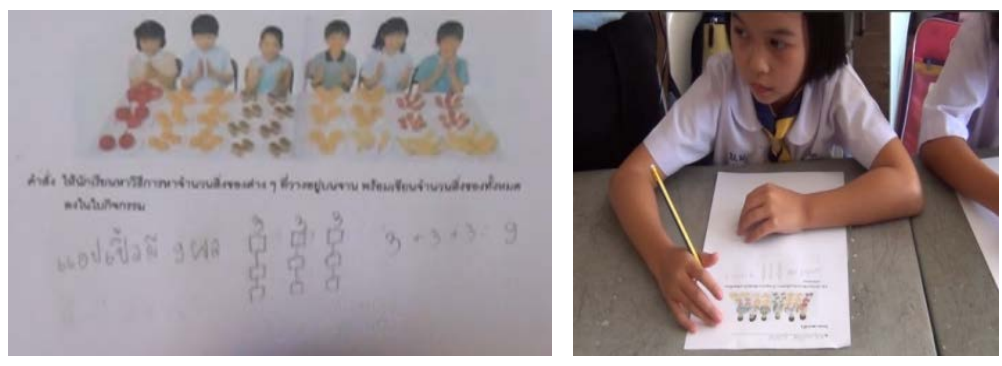
From the above protocol, it can be seen that Baitoey started by pairing the blocks she drew to find the number of apples. She then counted in multiples of three (increased in equal amounts at a time). Before Baitoey counted in threes, she evened the number of apples in each plate by drawing a line from the apples in the supplied images.

She then drew three rows of blocks, three blocks per row, and assigned the number " 3 " above each row of blocks.

In writing $3+3+3=9$, Baitoey intuitively discovered the method of repeated addition.

Baitoey figured out the method of repeated addition in order to reach a solution. According to Fishbein, Deri, Nello and Marino (1985) repeated addition is an "implicit, unconscious, and primitive intuitive model" for multiplication.

Baitoey proceeded to determine the number of other items. She tried to find the appropriate method for determining the number of oranges.

Baitoey: [Wrote the phrase "There are... oranges" and stopped. After about 10 seconds, she picked up the pencil, turned her face to look outside, brushed the paper with her hand three times, and then wrote " 24 oranges"].

Baitoey: [Drew a group of four blocks, two rows of two blocks, and wrote the number "4" above the group of blocks. This was rapidly repeated for another five times].

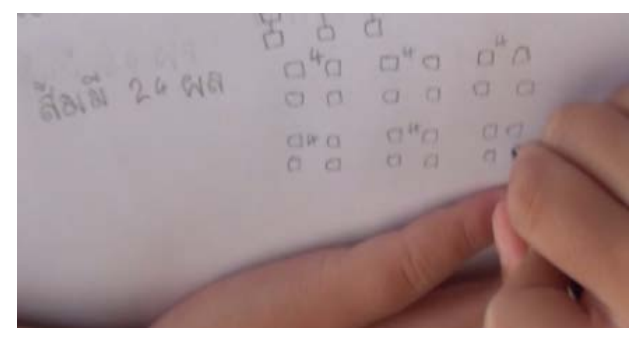

Baitoey: [Lifted her face up and looked sideway, moved her lips slightly and raised the pencil to write. She looked down at the paper, lifted her face once again and looked outside, repeatedly move her lips as if talking to herself].

Baitoey: [Wrote down $4+4+4+4=24$ and $4 \times 6=24$ ].

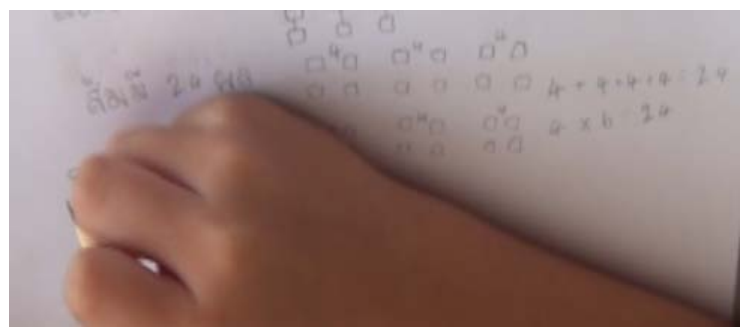

Teacher: [Pointed to the orange images, then pointed to the blocks that Baitoey drew].

What is this? What are these blocks that you drew? Are they oranges?

Baitoey: Oranges.

Teacher: How many ways are there?

Baitoey: There are three ways for the oranges.

Teacher: What is the first way?

Baitoey: Drawing blocks.

Teacher: What is the second way?

Baitoey: Four plus four, six times.

Teacher: Where did four multiplied by six come from? Where did four multiplied by six come from?

Baitoey: [Laughed gently and smiled].

Teacher: Where did four multiplied by six come from? Why did you write four multiplied by six?

Please give me the answer, there is no wrong answer. Why did you write four multiplied by six, Baitoey? 
I would like to know. Please tell me.

Baitoey: [Writing four multiplied by six. Thinking seriously and began to sweat].

Teacher: Why did you write four multiplied by six, Baitoey?

Baitoey: To understand quicker.

Teacher: To understand quicker. How? How will you understand quicker?

Baitoey: [Had a thoughtful face and pointed the pencil at $4 \times 6]$.

Teacher: Where did four come from? [Pointed at the number 4]

Baitoey: From the oranges.

Teacher: From the oranges. And where did the six come from?

Baitoey: There are six groups. [Pointed the pencil to the image and answered in low voice].

There are four members in each group. So I took four to multiply with six to get twenty-four [Spoke with confidence now].

From the above protocol, it can be seen that Baitoey counted the oranges in her head and wrote down " 24 oranges".

She then drew six groups of blocks, four blocks per group, and wrote "4" above each group. Baitoey intuitively used repeated addition to figure out the number of oranges. She also intuitively discovered multiplication when trying to find the number of oranges; this was shown through the equation $4+4+4+4=24$ and $4 \times 6=$ 24 that she wrote. Baitoey incorrectly wrote the symbols for repeated addition equation but returned to correct them.

Baitoey intuitively used repeated addition to determine the number of oranges. This indicates that she was confident with this method and also intuitively discovered the multiplication method to find the number of oranges.

Baitoey tried very hard to search for the answer through different methods. She eventually reduced the calculation step to the minimum, i.e. multiplying only two integers. Her reasoning was "To understand quicker". The reason she knew how to use the " $\times$ " symbol was because the teacher started training the students to remember multiplication tables about one week ago.

Baitoey's method was to draw groups of blocks with an equal amount of members and wrote the number down to represent the amount of the members in each group. She used the same method for finding the number of oranges to figure out the number of the cakes, donuts, and strawberries. This shows that Baitoey was confident with using this method to figure out the amount of the different items the question asked.

Baitoey proceeded to figure out the number of bananas through the following protocol;

Baitoey: [Wrote "There are 13 bananas" and drew pictures].

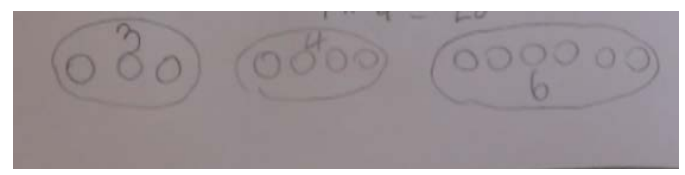

Baitoey: [Pondered the problem so hard that she sweated].

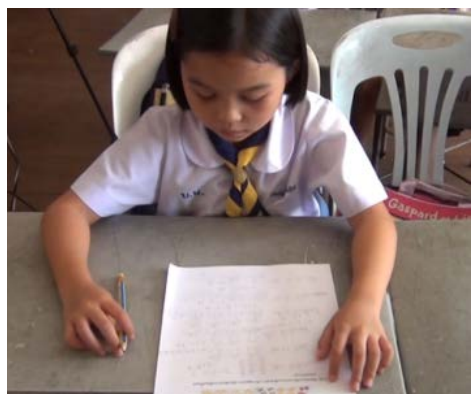

Teacher: This one is three. This one is four. This one is six. What will you do?

Baitoey: [Grinned widely and shook her head] I can't do it.

Baitoey: [Drew three groups of bananas - two groups with five bananas and the other one with three bananas]. 


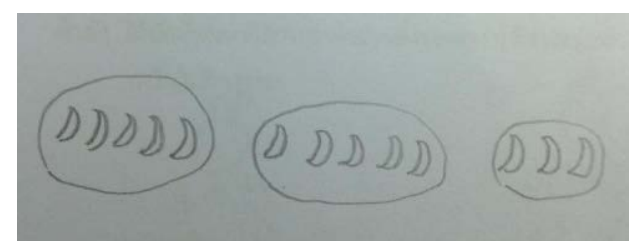

Baitoey made great effort to split the bananas into groups of even members so that she could use addition and multiplication methods to determine the number of bananas. This made Baitoey intuitively conceived a new idea that 13 items cannot be separated into three groups of even members. She was unable to tell whether the 13 items could be put into groups of one member or only one group because she had yet to understand the basis for a multiplication by one (Figure 3).

Step 3: Whole-class discussion and comparison.

In the whole classroom discussion and comparison step, the teacher observed the development of the students' ideas in Step 2 and selected student representatives to present their ideas in front of the class. The presentation was to allow the class to learn from their friend's ideas, which they can object or accept. Students can return to check their own ideas after having solved the problems in Step 2 (Figure 4).

In this step, Baitoey demonstrated the method she used to figure out the number of apples with multiplication. When the teacher asked Baitoey to show how to figure out the number of donuts by repeatedly adding 3 for 5 times, she presented her method with confidence and a smiling face. It was obvious that despite initially using multiplication method to find the number of apples, Baitoey chose to demonstrate the repeated addition method when asked to do so the second times. This may be because Baitoey has not yet comprehended the meaning of multiplication so she was more confident with the repeated addition method.

The ideas or methods demonstrated by students in this step include counting one item at a time, counting in equal increments, adding the number of items in each group, and distributing the items in equal number to each group and using the repeated addition method. The last method was then expanded to the multiplication method.

Step 4: Summarization through connecting students' mathematical ideas that emerged in the classroom.

The teacher led a conclusion session in order to connect the students' ideas that emerged in the classroom. She summarized the ideas of the selected students who made class presentations on how to derive the total number of each items, using donuts as an example. The selected students presented their ideas in words such as: "Three is the number of the group's members"; "There are five groups"; "Three plus three five times equal fifteen". To the teacher's question of "What topic did we learn today?", the students' answers were: "A party", "Arithmetic", "Mathematics", and "Addition". We can see from these answers that there was no such word as "Multiplication" from the students since addition was the students' existing knowledge and what they had learned so far. This was the first class that the students were confronted with a multiplication situation. They had not yet learned the meaning of multiplication; this was to be the topic of their next mathematics class.

Data in the field record gathered through individual interviews. Subsequently, Baitoey was interviewed and requested to explain by what method she reached an answer.

Researcher: Please tell me what multiplication methods you figure out the total number of sweets and fruits.

Baitoey: Three ways.

Researcher: What is your addition?

Baitoey: I completed equal groups. In each group, it has same numbers. Then, I added the numbers.

Researcher: What is your multiplication?

Baitoey: I made equal groups. In each group, there are equal members. So, I took numbers to multiply groups.

Then, I multiplied them.

From the above interview, it illustrated Baitoey's multiplication methods. Accordingly, she used counting in equal increments and distributing the items in equal number to each group. Afterward, she used the repeated addition method and then it was expanded in the multiplication method for total number of each type of the items.

\section{Conclusion}

Mathematics class that uses Lesson Study and Open Approach provides students with an opportunity to form intuitive understanding of basic multiplication. Students' intuition is developed in Step 1-Posing open-ended question and Step 2-Students' self-learning through the problem-solving method of Open Approach. Students 


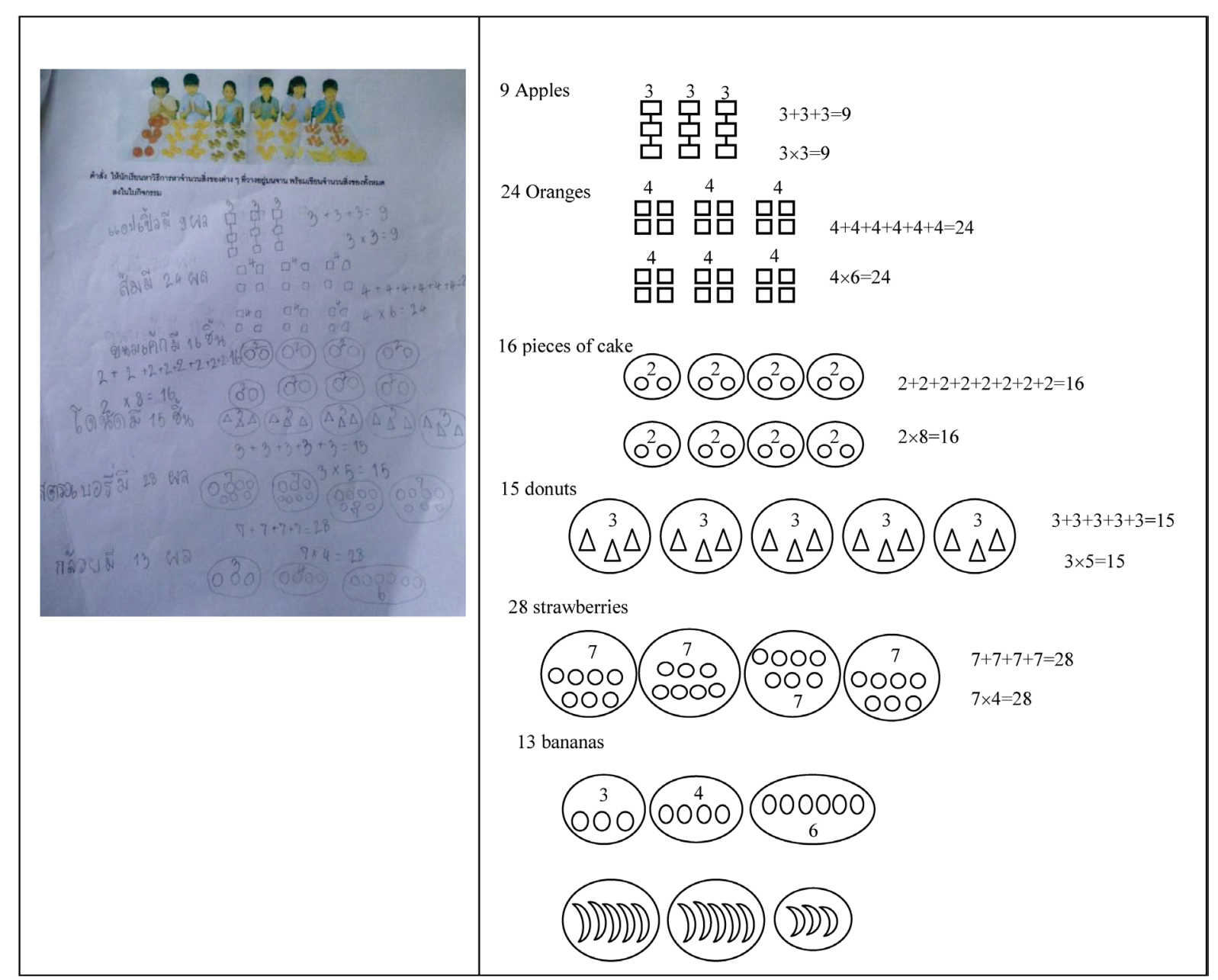

Figure 3. Baitoey’s work.
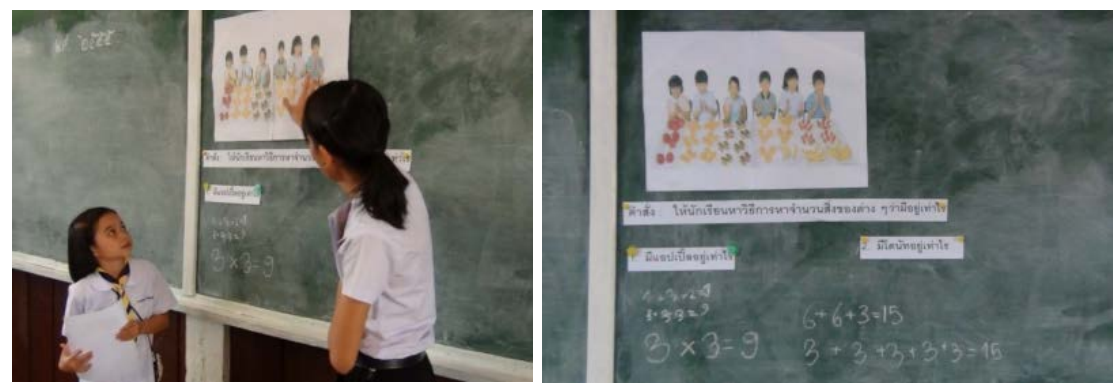

Figure 4. Students join in the discussion.

intuitively discovered the repeated addition and multiplication methods in solving multiplication problems. Teachers who use Lesson Study as the tool to design problem situations, anticipate students' thinking style, and design the 4-step Open Approach teaching method that will enable students to handle their intuition. In 4-step Open Approach teaching, students displayed the following problem-solving behaviors: Step 1, Posing openended problem. Students show enthusiasm and the desire to solve the problem on their own. They expect to do so by using the knowledge that they have already acquired before trying to solve the problem by themselves; Step 2, Students' self-learning through problem solving. Students show an effort to solve the problem by themselves. When they understand the situation on their own, students will try very hard to experiment with the different methods that they have previously learned. By experimenting, students will reject the inappropriate me- 
thod. They will momentarily feel that they have discovered the right problem-solving method for a particular problem. This method which momentarily dawn on the students will enable them to discover a method or a solution to the problem. After discovering the solution or the method to solve the problem, students will show more attempt to discover the right method for the next problem. Students will return to review the method that they have previously demonstrated while solving problems. They will momentarily feel that they have discovered a new method or new idea; Step 3, Whole class discussion and comparison. Students will listen to friends' and teachers' ideas and think back to the method that they have used to solve the problem. They will give reasons for the use of such method and review their own method. Students will value their own methods or ideas as well as their friends' methods or ideas, perceiving them as the most suitable method or idea for the problem; Step 4, Summarization through connecting students' mathematical ideas emerged in the classroom. Students are found to be able to make a verbal summary of what they have learned and the benefits of the method or idea that they have developed through problem solving.

\section{Discussion}

The importance of this research finding is multiplication problems in situations given in a mathematics class. Apparently, students should be encouraged to solve the problems in their own methods. The data were collected from a mathematics class using Lesson Study and Open Approach. In addition, three students were the target group as purposive selection. The selected students are enthusiastic to solve a problem and assured to give opinions in the participation of the mathematics class. Therefore, students' intuitive understanding and continuous problem solving are logically clarified.

\section{Acknowledgements}

This research is supported by Center for Research in Mathematics Education, Khon Kaen University, Thailand.

\section{References}

Anghileri, J. (1989). An Investigation of Young Children’s Understanding of Multiplication. Educational Studies in Mathematics, 20, 367-385. http://dx.doi.org/10.1007/BF00315607

Baba, T. (2007). Japanese Education and Lesson Study: An Overview. In M. Isoda, M. Stephen, Y. Ohara \& T. Miyakawa (Eds.). Japanese Lesson Study in Mathematics: Its Impact, Diversity and Potential for Educaional Improvement (pp. 2-7). Singapore: World Scientific Publishing. http://dx.doi.org/10.1142/9789812707475_0001

Ben-Zeev, T., \& Star, J. (2001). Intuitive Mathematics: Theoretical and Educational Implications. In B. Torff \& R. J. Sternberg (Eds.), Understanding and Teaching the Intuitive Mind: Student and Teacher Learning (pp. 29-56). Mahwah, NJ: Lawrence Erlbaum.

Bruner, J. (1960). The Process of Education. London: Oxford University.

Fischbein, E. (1987). Intuition in Science and Mathematics. Dordrecht: Reidel.

Fischbein, E. (1994). The Interaction between the Formal, the Algorithmic, and the Intuitive Components in a Mathematical Activity. In R. Biehler, R. W. Scholz, R. Sträber, \& B. Winkelmann (Eds.), Didactics of Mathematics as a Scientific Discipline (pp. 231-245). Dordrecht: Kluwer Academic.

Fischbein, E. (1999). Intuitions and Schema in Mathematical Reasoning. Educational Studies in Mathematics, 38, 11-50. http://dx.doi.org/10.1023/A:1003488222875

Fischbein, E., Deri, M., Nello, M. S., \& Marino, M. S. (1985). The Role of Implicit Models in Solving Verbal Problems in Multiplication and Division. Journal for Research in Mathematics Education, 16, 3-17. http://dx.doi.org/10.2307/748969

Gakkoh Tosho Co., Ltd. (2005). Study with Your Friends MATHEMATICS for Elementary School 2nd Grade. Tokyo: Gakkotosho.

Gelman, R (1980). What Young Children Know about Numbers. Educational Psychologist, 15, 54-68. http://dx.doi.org/10.1080/00461528009529216

Gelman, R. (1982). Basic Numerical Abilities. In R. J. Sternberg (Ed.), Advances in the Psychology of Human Intelligence (pp. 181-205). Hillsdale, Lawrence Erlbaum Associates.

Ikeda, T. (2010). Roots of the Open-Ended Approach: Introduction. Special Issue (EARCOME5) Mathematics Education Theories for Lesson Study: Problem Solving Approach and the Curriculum through Extension and Integration. Journal of 
Japan Society of Mathematical Education, 6-7.

Inprasitha, M. (2003). Reforming of Mathematics Learning in School Focusing on Mathematical Process. Khonkhan. Khonkhan Publishing.

Inprasitha, M., \& Loipha, S. (2004). Innovative Teachers Professional Development to Promote Mathematics Learning. KKU Journal of Mathematics Education, 1, 18-28.

Inprasitha, M. (2006). Open-Ended Approach and Teacher Education. Tsukuba Journal of Educational Study in Mathematics, 25, 169-178.

Inprasitha, M. (2010). One Feature of Adaptive Lesson Study in Thailand: Designing Learning Unit. In C. S. Cho, S. G. Lee, \& Y. H. Choe (Eds.). Proceedings of the 45th National Meeting of Mathematics Education, Korea: Dongkook University, Gyeongju, 193-206.

Kilpatrick, J. (1992). A History of Research in Mathematics Education. In D. Grouws (Ed.), Handbook of Research on Mathematics Teaching and Learning (pp. 3-38). New York: Macmillan.

Mulligan, J. T., \& Michelmore, M. C. (1997). Young Children's Intuitive Models of Multiplication and Division. Journal for Research in Mathematical Education, 28, 309-330. http://dx.doi.org/10.2307/749783

Nohda, N. (2000). Teaching by Open-Approach Method in Japanese Mathematics Classroom. Proceeding of the 24th Conference of the International Group for the Psychology of Mathematics Education (PME 24), Hiroshima, Japan: Hiroshima University, 39-54.

Polya, G. (1954). Mathematics and Plausible Reasoning (Volume II): Patterns of Plausible Inference. Princeton, NJ: Princeton University Press.

Thurston, W. P. (1990). Mathematical Education. Notices of the American Mathematical Society, 37, 844-850.

Yoshida, M. (2008). Exploring Ideas for a Mathematics Teacher Educator’s Contribution to Lesson Study. In D. Tirosh, \& T. Wood (Eds.), Tools and Process in Mathematics Teacher Education (pp. 85-106). Rotterdam: Sense Publishers. 
Scientific Research Publishing (SCIRP) is one of the largest Open Access journal publishers. It is currently publishing more than 200 open access, online, peer-reviewed journals covering a wide range of academic disciplines. SCIRP serves the worldwide academic communities and contributes to the progress and application of science with its publication.

Other selected journals from SCIRP are listed as below. Submit your manuscript to us via either submit@scirp.org or Online Submission Portal.
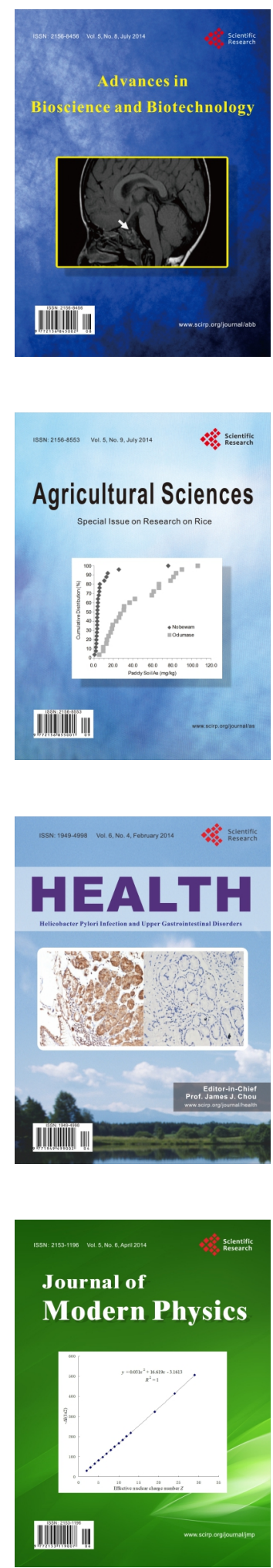
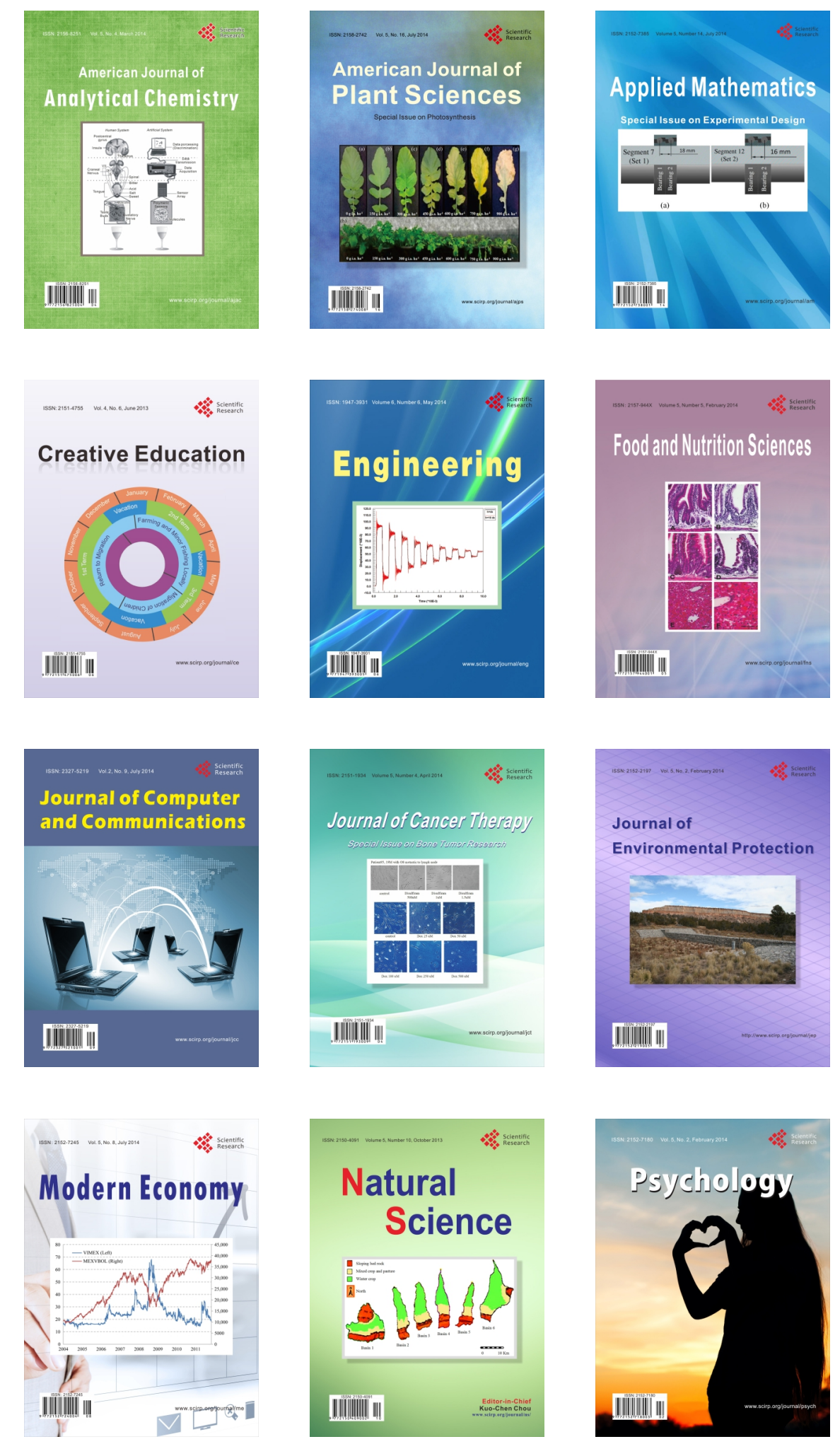